\title{
CONTROL OF SYNCHRONIZATION VIA A SECOND ORDER FILTER CONTROLLER*
}

\author{
T. Pyragienè, K. Pyragas, A. Tamaševičius, G. Mykolaitis \\ Semiconductor Physics Institute, A. Goštauto 11, LT-01108 Vilnius, Lithuania \\ E-mail: pyragiene@pfi.lt
}

Received 15 June 2007

\begin{abstract}
A simple controller based on a second order active filter is applied to extend the synchronization region of a forced weakly nonlinear self-sustained oscillator. The controller stabilizes unstable periodic orbits that exist in the uncontrolled system outside the synchronization region. The control algorithm is non-invasive in the sense that it uses only small control perturbations. We present analytical and numerical results as well as an experimental demonstration.
\end{abstract}

Keywords: non-invasive control, synchronization, self-sustained oscillations, unstable periodic orbits

PACS: 05.45.Xt, 05.45.Gg, 02.30.Yy

\section{Introduction}

Synchronization is a natural property of interacting self-sustained oscillators, intensively studied in many physical, chemical, and biological systems [1]. Synchronization effects are widely used in engineering, for example, for improvement of the line width of a highpower generator with the help of a low-power generator having a narrower spectral line. In biological systems, abnormal physiological oscillations (e.g. heart beat disorders) can be normalized via synchronization by appropriate external or internal stimuli [2].

In many practical applications the need arises to control the synchronization phenomenon. The engineers and applied mathematicians have been dealing with control problems for a long time and a huge amount of knowledge has been gathered [3,4]. An idea of non-invasive control has been emphasized by physicists one and a half decade ago in the context of controlling chaos [5]. The non-invasive control assumes that the control force vanishes when the target state is reached. The key idea is based on exploiting inherent unstable periodic orbits (UPOs) embedded in a strange attractor of chaotic system; these UPOs can be stabilized with only tiny perturbations. Following the pioneering paper [5], many different control techniques of such type have been proposed (see [6] and references therein). The non-invasive control techniques are attractive not

\footnotetext{
* The report presented at the 37th Lithuanian National Physics Conference, 11-13 June 2007, Vilnius, Lithuania.
}

only because they require less energy cost, but their intervention into the controlled system is minimal as well. The latter property is particularly important for application to biological systems.

We have recently adapted the idea of non-invasive control for extending the synchronization region of a periodically forced self-sustained oscillator $[7,8]$. It is common knowledge that a weakly nonlinear selfsustained oscillator can be synchronized by an external force only in a certain region of parameters, namely, when the amplitude of the external force is sufficiently large and the frequency detuning is sufficiently small. Outside the region of synchronization the oscillator exhibits a quasi-periodic motion, however, the quasiperiodic regime is characterized by the presence of UPOs. These UPOs can be stabilized by a tiny feedback perturbation and thus the region of synchronization can be extended non-invasively. We have considered two methods of non-invasive control. One of them [7] uses the well-known delayed feedback control (DFC) algorithm [9], and another [8] is based on constructing a backward time replica of the original oscillator that has the same UPOs as the original but with opposite stability properties. Both methods have some advantages and shortcomings and the specific choice of the method is dictated by the convenience of the situation. The DFC is a model-independent algorithm while the backward time control (BTC) method requires the knowledge of the system equations. Here we apply an alternative model-independent control algorithm [10], 


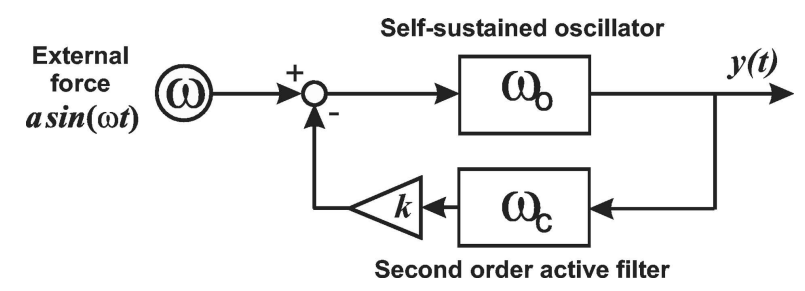

Fig. 1. Block diagram of a control technique based on a second order active filter.

which is simpler to implement in experiment than the DFC. In this method, a second order active filter is employed instead of a delay line used in the DFC method. We analyse both stable and unstable filters and show that in some situations the unstable filter may be more appropriate than the stable one.

The remainder of the paper is as follows. Section 2 is devoted to the description of the control algorithm and the problem formulation. In Section 3, we derive amplitude equations for the controlled weakly nonlinear van der Pol oscillator and perform linear stability analysis. Section 4 is devoted to numerical and experimental demonstrations of the system dynamics under control. The paper is finished with conclusions in Section 5 .

\section{Control algorithm and problem formulation}

Consider a self-sustained oscillator driven by an external periodic force. In a certain region of parameters, the oscillator is synchronized by the external force, however, due to drift of parameters the synchronization may be lost and a beat phenomenon may appear. Suppose that our aim is to maintain the synchronous regime in the presence of the drift. Imagine that we cannot control the parameters of the external force, but there is some dynamic variable of the oscillator accessible for experimental observation and we can influence the dynamics of the oscillator through some accessible input. We seek to construct a feedback controller that makes the synchronization region as large as possible. We want to achieve this non-invasively by exploiting the UPOs lying outside the synchronization region.

To control the synchronization region we introduce a controller based on a second order active filter. The block diagram of the control technique is shown in Fig. 1. By $\omega_{0}$ and $\omega_{\mathrm{c}}$ are denoted the characteristic frequencies of the self-sustained oscillator and the filter, respectively; $a$ is the amplitude and $\omega$ is the frequency of external force, $k$ is the strength of the feedback signal.
In our theoretical considerations, we specify a selfsustained oscillator by the van der Pol equation. Then the theoretical model of the control technique diagrammed in Fig. 1 can be presented in the form

$$
\begin{aligned}
\ddot{x}+\omega_{0}^{2} x+\varepsilon\left(x^{2}-1\right) \dot{x}= & a \sin (\omega t)- \\
& -k(\dot{x}-q \dot{u}-p u), \\
\ddot{u}+\omega_{\mathrm{c}}^{2} u+b \dot{u}= & \dot{x} .
\end{aligned}
$$

The left-hand side of Eq. (1) represents the standard van der Pol equation. The parameter $\varepsilon$ is responsible for the strength of nonlinearity of the oscillator. The first term in the right-hand side is an external periodic force and the second term describes the control perturbation. Equation (2) defines the controller, a second order filter described by dynamic variables $u$ and $\dot{u}$. We suppose that $\dot{x}$ is an observable output of the oscillator and use it as an input of the filter in the right-hand side of Eq. (2). The output of the filter $\dot{x}-q \dot{u}-p u$ (the last term in the right-hand side of Eq. (1)) is constructed as a linear combination of the input variable $\dot{x}$ and dynamic variables of the filter $u$ and $\dot{u}$. The values of the parameters $p$ and $q$ will be determined below. The parameter $b$ is the damping coefficient of the filter. We will consider both the positive and negative values of this parameter, which correspond respectively to the stable and unstable filter. Here we show that the unstable filter can improve the controller performance for small amplitudes of the driving force.

\section{Amplitude equations and linear stability analysis}

The system (1)-(2) admits an analytical treatment if the following inequalities are met:

$$
\begin{aligned}
& \frac{\varepsilon}{\omega_{0}} \ll 1, \quad \frac{a}{\omega_{0}^{2}} \ll 1, \quad \frac{k}{\omega_{0}} \ll 1, \quad \frac{|b|}{\omega_{0}} \ll 1, \\
& \frac{\left|\omega-\omega_{0}\right|}{\omega_{0}} \ll 1, \quad \frac{\left|\omega-\omega_{\mathrm{c}}\right|}{\omega_{0}} \ll 1 .
\end{aligned}
$$

In this case Eqs. (1)-(2) describe weakly perturbed harmonic oscillators with eigenfrequencies $\omega_{0}$ and $\omega_{\mathrm{c}}$ close to the frequency $\omega$ of the external force, or more precisely, the system is close to a Hopf bifurcation. For such a system we can apply the method of averaging. First we rewrite Eqs. (1)-(2) as a system of ordinary differential equations of the first order

$$
\dot{x}=y,
$$




$$
\begin{aligned}
& \dot{y}=-\omega_{0}^{2} x-\varepsilon\left(x^{2}-1\right) y+ \\
& \quad+a \sin (\omega t)-k(y-q v-p u), \\
& \dot{u}=v, \\
& \dot{v}=-\omega_{\mathrm{c}}^{2} u-b v+y .
\end{aligned}
$$

We look for solutions of the system (4)-(7) in the form

$$
\begin{aligned}
& x=\frac{1}{2}\left[A(t) \mathrm{e}^{\mathrm{i} \omega t}+A^{*}(t) \mathrm{e}^{-\mathrm{i} \omega t}\right], \\
& y=\frac{\mathrm{i} \omega}{2}\left[A(t) \mathrm{e}^{\mathrm{i} \omega t}-A^{*}(t) \mathrm{e}^{-\mathrm{i} \omega t}\right], \\
& u=\frac{1}{2}\left[B(t) \mathrm{e}^{\mathrm{i} \omega t}+B^{*}(t) \mathrm{e}^{-\mathrm{i} \omega t}\right], \\
& v=\frac{\mathrm{i} \omega}{2}\left[B(t) \mathrm{e}^{\mathrm{i} \omega t}-B^{*}(t) \mathrm{e}^{-\mathrm{i} \omega t}\right] .
\end{aligned}
$$

Here $A(t)$ and $B(t)$ are new variables, slowly varying complex amplitudes. Putting Eqs. (8)-(9) into system (4)-(7) and averaging over the period $T=2 \pi / \omega$ of fast oscillations we obtain the equations for the complex amplitudes

$$
\begin{aligned}
\dot{A}= & \frac{\omega^{2}-\omega_{0}^{2}}{2 \mathrm{i} \omega} A-\frac{\varepsilon}{2} A\left(\frac{|A|^{2}}{4}-1\right)-\frac{a}{2 \omega}- \\
& -k\left(\frac{1}{2} A-\frac{q}{2} B-\frac{p}{2 \mathrm{i} \omega} B\right), \\
\dot{B}= & \frac{\omega^{2}-\omega_{\mathrm{c}}^{2}}{2 \mathrm{i} \omega} B-\frac{b}{2} B+\frac{1}{2} A .
\end{aligned}
$$

For $k=0$, the steady state solutions of Eq. (10) define the stationary amplitudes $A_{0}$ of a forced oscillator without control. The control algorithm will be noninvasive if the control perturbation does not change these stationary solutions. The requirement is fulfilled if the right-hand side of Eq. (11) and the control perturbation (the last term proportional to $k$ in Eq. (10)) turns to zero simultaneously. This happens if the following equalities take place:

$$
q=b, \quad p=\omega_{\mathrm{c}}^{2}-\omega^{2} .
$$

Conditions (12) represent the main requirement for the controller parameters which makes the control algorithm non-invasive. In the following we suppose that these conditions are satisfied.
To simplify Eqs. (10)-(11) we rescale the amplitudes

$$
A=2 Z, \quad B=2 W
$$

and introduce new parameters

$$
\begin{aligned}
& \alpha=\frac{a}{2 \varepsilon \omega}, \quad \nu=\frac{\omega^{2}-\omega_{0}^{2}}{\varepsilon \omega} \approx 2 \frac{\omega-\omega_{0}}{\varepsilon}, \\
& \kappa=\frac{k}{\varepsilon}, \quad \nu_{\mathrm{c}}=\frac{\omega^{2}-\omega_{\mathrm{c}}^{2}}{\varepsilon \omega}, \quad \gamma=\frac{b}{\varepsilon} .
\end{aligned}
$$

Then Eqs. (10)-(11) take the form

$$
\begin{aligned}
& \frac{2}{\varepsilon} \dot{Z}=-\mathrm{i} \nu Z-Z\left(|Z|^{2}-1\right)-\alpha-\kappa \frac{2}{\varepsilon} \dot{W}, \\
& \frac{2}{\varepsilon} \dot{W}=-\mathrm{i} \nu_{\mathrm{c}} W-\gamma W+Z .
\end{aligned}
$$

The parameters $\nu$ and $\nu_{\mathrm{c}}$ define the frequency detuning of the van der Pol oscillator and filter, respectively; $\kappa$ is a rescaled value of the control gain, and $\gamma$ is a rescaled value of the filter damping.

We start the analysis of the system (15)-(16) from finding stationary solutions. Setting $\dot{Z}=0, \dot{W}=0$ and $Z=Z_{0}, W=W_{0}$ we obtain

$$
\begin{aligned}
& -\mathrm{i} \nu Z_{0}-Z_{0}\left(\left|Z_{0}\right|^{2}-1\right)-\alpha=0, \\
& W_{0}=\frac{Z_{0}}{\mathrm{i} \nu_{\mathrm{c}}+\gamma} .
\end{aligned}
$$

The stationary values of the oscillator amplitude $Z_{0}$ are defined by Eq. (17), which does not depend on the filter variables. Thus the controller does not change the periodic solutions of the forced oscillator with period $T$, however, as will be apparent below, it can change their stability. To solve Eq. (17) we introduce the notations

$$
s=\left|Z_{0}\right|^{2}, \quad f_{\nu}(s)=s\left[(s-1)^{2}+\nu^{2}\right] .
$$

Then the stationary values of $s$ can be found by solving the cubic equation

$$
f_{\nu}(s)=\alpha^{2}
$$

with respect to $s$. Knowing $s$, from Eqs. (17)-(18) one can easily determine the steady state values $Z_{0}$ and $W_{0}$. Note that the radius of periodic orbit in the $(x, y)$ plane is defined by $\left|A_{0}\right|=2\left|Z_{0}\right|=2 \sqrt{s}$. Equation (20) has three real roots provided

$$
\begin{aligned}
& \alpha_{1}^{2}(\nu)<\alpha^{2}<\alpha_{2}^{2}(\nu) \\
& \alpha_{1,2}^{2}(\nu)=\frac{2}{27}\left[9 \nu^{2}+1 \mp\left(1-3 \nu^{2}\right)^{3 / 2}\right]
\end{aligned}
$$




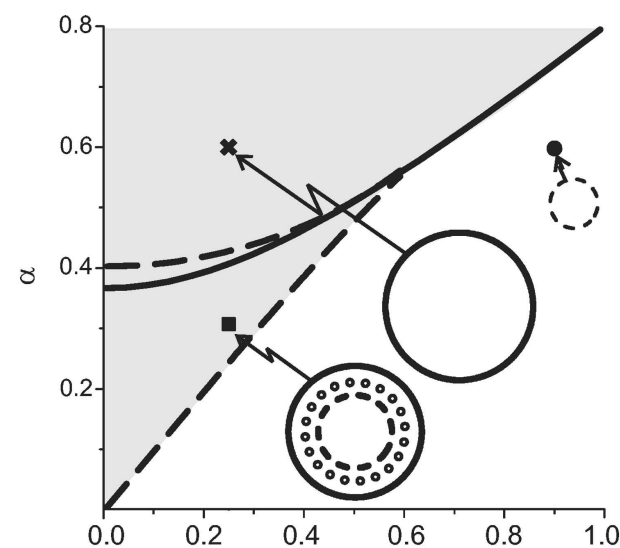

(a)

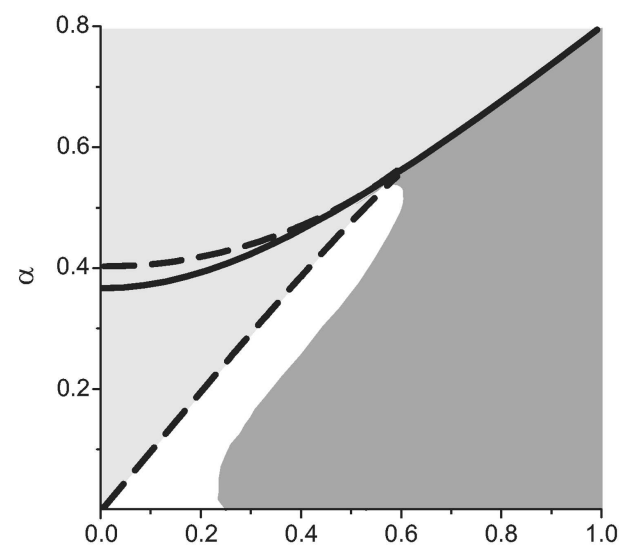

(c)

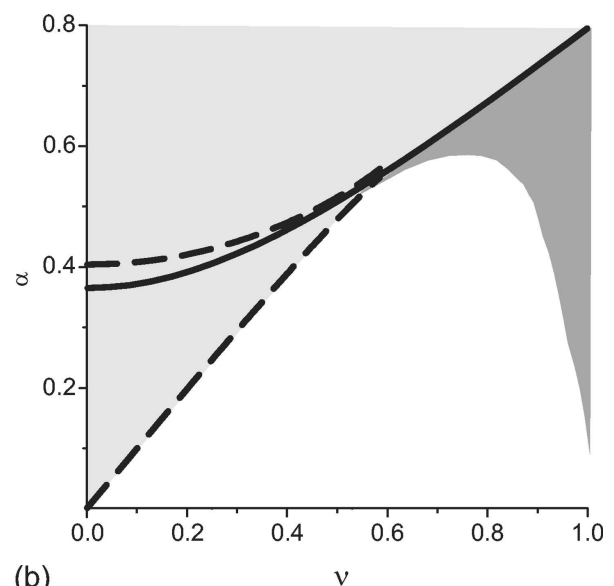

(b)

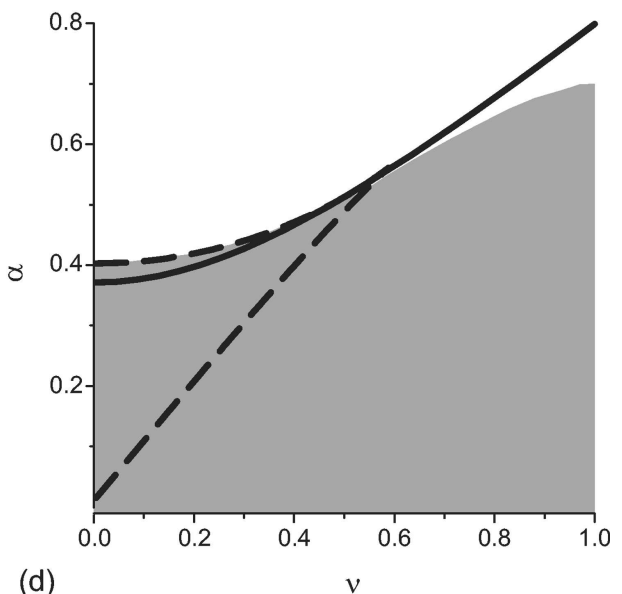

Fig. 2. The bifurcation diagrams of a forced oscillator (a) without control, and under control with the use of (b, c) stable and (d) unstable filters. The dashed lines are defined by Eq. (22). The region between these lines correspond to three periodic orbits. Outside this region there is only one periodic orbit. The solid line is the hyperbola (31) defining the Hopf bifurcation of the uncontrolled oscillator. Examples of periodic orbits in different regions of the bifurcation diagram are shown in (a). The synchronization region of the uncontrolled oscillator

(the original Arnold tongue) is shown in grey. Extended areas of the synchronization region due to control are depicted in dark grey.

or one real root otherwise. Thus the forced van der Pol oscillator has either three or one periodic orbit(s). Figure 2(a) shows the bifurcation diagram of the uncontrolled oscillator $(\kappa=0)$ in the plane of parameters $(\nu, \alpha)$. Since it is symmetrical with respect to the $\nu$ and $\alpha$ axes, only the part $\nu \geq 0, \alpha \geq 0$ is presented. The region with three orbits is between thick dashed lines. Outside this region there is only one periodic orbit. Some typical periodic orbits (in the $(x, y)$ plane) taken from different regions of the bifurcation diagram at some fixed values of the parameters $(\nu, \alpha)$ are shown in Fig. 2(a).

To determine the stability of periodic orbits, we linearize Eqs. (15)-(16) around the stationary solution $Z=Z_{0}, W=W_{0}$ and obtain the characteristic equation

$$
\Lambda^{4}+a_{3} \Lambda^{3}+a_{2} \Lambda^{2}+a_{1} \Lambda+a_{0}=0 .
$$

Here we use the notation $\Lambda=2 \lambda / \varepsilon$, where $\lambda$ is the eigenvalue of the linearized Eqs. (15)-(16), which coincides with the Floquet exponent (FE) of the corresponding periodic orbit. The coefficients of the polynomial in Eq. (23) are

$$
\begin{aligned}
a_{0}= & \left(\nu_{\mathrm{c}}^{2}+\gamma^{2}\right) f_{\nu}^{\prime}(s), \\
a_{1}= & 2 \gamma f_{\nu}^{\prime}(s)+2\left(\nu_{\mathrm{c}}^{2}+\gamma^{2}\right)(2 s-1)+ \\
& +2\left[\gamma(2 s-1)-\nu \nu_{\mathrm{c}}\right] \kappa, \\
a_{2}= & f_{\nu}^{\prime}(s)+4 \gamma(2 s-1)+\nu_{\mathrm{c}}^{2}+\gamma^{2}+ \\
& +2(\gamma+2 s-1) \kappa+\kappa^{2}, \\
a_{3}= & 2(\gamma+2 s-1+\kappa),
\end{aligned}
$$


where $s$ is the solution of the cubic equation (20) and

$$
f_{\nu}^{\prime}(s)=(3 s-1)(s-1)+\nu^{2}
$$

is the derivative of the function $f_{\nu}(s)$ defined in Eq. (19).

First we discuss the stability of periodic orbits of the uncontrolled system for $\kappa=0$. In this case the fourth order polynomial (23) can be presented as a product of two second order polynomials and the eigenvalues are defined by two independent quadratic equations

$$
\begin{aligned}
& \Lambda^{2}-2(1-2 s) \Lambda+f_{\nu}^{\prime}(s)=0, \\
& \Lambda^{2}+2 \gamma \Lambda+\nu_{\mathrm{c}}^{2}+\gamma^{2}=0 .
\end{aligned}
$$

They define the eigenvalues of two independent subsystems: Eq. (29) corresponds to the uncontrolled oscillator, while Eq. (30) describes the eigenvalues of the free filter. The eigenvalues of the free filter are $\Lambda_{1,2}=-\gamma \pm \mathrm{i} \nu_{\mathrm{c}}$. The characteristic Eq. (29) defining the stability of periodic orbits of the uncontrolled oscillator depends on the parameter $s$, i. e., on the amplitude of the orbit $\left|A_{0}\right|=2 \sqrt{s}$. Two different types of bifurcations may occur in the system. For $f_{\nu}^{\prime}(s)=$ 0 we have a tangent (saddle-node) bifurcation, and for $s=1 / 2$ a Hopf bifurcation occurs. The Hopf bifurcation defines the minimal amplitude of the stable orbit $A_{\text {min }}=\sqrt{2}$. The orbits with amplitude $\left|A_{0}\right|<A_{\text {min }}$ are unstable. In the $(\nu, \alpha)$ plane, this condition defines the hyperbola

$$
\alpha^{2}=f_{\nu}\left(\frac{1}{2}\right)=\frac{\nu^{2}}{2}+\frac{1}{8},
$$

which is shown by a solid line in Fig. 2(a). Above this line the oscillator is synchronized with the external force. The condition of the saddle-node bifurcation $f_{\nu}^{\prime}(s)=0$ defines the boundaries $\alpha^{2}=\alpha_{1,2}^{2}(\nu)$ of the region with three periodic orbits in the $(\nu, \alpha)$ plane (dashed solid lines in Fig. 2(a)). In this region the largest orbit is stable, while two other orbits are unstable. The middle orbit is of a saddle type; it satisfies the condition $f_{\nu}^{\prime}(s)<0$ and has two real FEs of different signs. The smallest orbit is unstable and has a pair of complex conjugate FEs. In Fig. 2(a) the stable orbits are depicted by solid lines, the unstable orbits with a pair of complex conjugate FEs are shown by dashed lines, and the saddle orbit is marked by open circles. The grey region in the $(\nu, \alpha)$ plane, where at least one orbit is stable, corresponds to the synchronized motion of the oscillator and is known as the Arnold tongue.

We now analyse the stability of periodic orbits for the closed feedback loop when $\kappa \neq 0$. The stability conditions of the polynomial (23) can be determined from the Hurwitz criterion

$$
\begin{aligned}
& a_{0}>0, \quad a_{3}>0, \quad a_{3} a_{2}-a_{1}>0, \\
& a_{3}\left(a_{1} a_{2}-a_{0} a_{3}\right)-a_{1}^{2}>0 .
\end{aligned}
$$

If these inequalities are satisfied, all the roots of Eq. (23) are in the left half-plane, $\operatorname{Re} \Lambda<0$. From the first inequality $a_{0}>0$ and Eq. (24) it follows that the necessary stability condition is $f_{\nu}^{\prime}(s)>0$. In the following we analyse the stability of UPOs with complex conjugate pair of FEs, which are depicted in Fig. 2(a) by dashed lines. Figures $2(b-d)$ show an extension of the Arnold tongue due to the stabilization of these orbits. The regions of stability are obtained from conditions (32) for $\nu_{\mathrm{c}}=0\left(\omega_{\mathrm{c}}=\omega\right)$ and different values of parameters $\gamma$ and $\kappa$. In this paper we do not analyse the case $\nu_{\mathrm{c}} \neq 0$, which leads to non-symmetrical bifurcation diagram with respect to the transformation $\nu \rightarrow-\nu$. The cases (b) and (c) correspond to a stable filter $(\gamma>0)$, while the case (d) represents an unstable filter $(\gamma<0)$. The analysis show that if we fix $\gamma$ and increase $\kappa$ then the region of synchronization first increases and then again decreases. In other words, for a fixed $\gamma$, there exists an optimal value $\kappa_{\text {max }}$ for which this region is maximal. In the figures we show maximal synchronization regions for different values of $\gamma$ and $\kappa=\kappa_{\max }$. From Figs. 2(b) and (c) we see that in the case of a stable filter the Arnold tongue can be essentially enlarged if the damping coefficient $\gamma$ is sufficiently small. This can be partially explained by a frequency domain analysis of the transfer function of the filter

$$
H(\Omega)=\frac{\omega^{2}-\Omega^{2}}{\omega_{\mathrm{c}}^{2}-\Omega^{2}+\mathrm{i} \Omega \varepsilon \gamma} .
$$

For $\omega_{\mathrm{c}}=\omega$ and small $\gamma$, the transfer function is approximately equal to unity, $H(\Omega) \approx 1$, almost for all frequencies $\Omega$, except a narrow window close to $\Omega \approx \omega$, and it vanishes for $\Omega=\omega$. Thus the controller does not change the first harmonic of a periodic orbit of the frequency $\omega$ and provides a negative feedback for all other frequencies.

The stable filter is ineffective to stabilize small periodic orbits in the region where the system has three periodic orbits. As evident from Fig. 2(d), the region of small amplitudes $\alpha$ can be effectively controlled by the unstable filter $(\gamma<0)$. It is interesting to note that the unstable filter inverts the synchronization region; the large periodic orbits in the original Arnold tongue become unstable, and the small orbits inside and outside the original Arnold tongue become stable. 


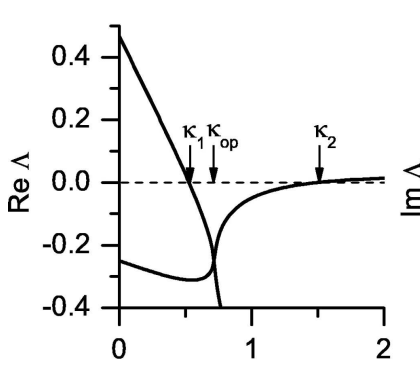

(a)

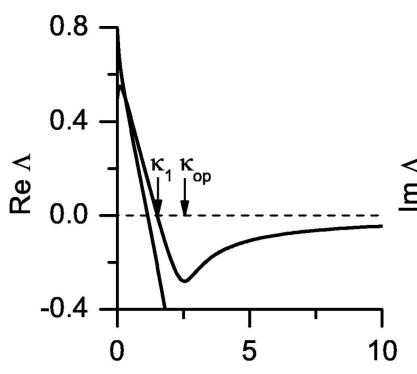

(c)

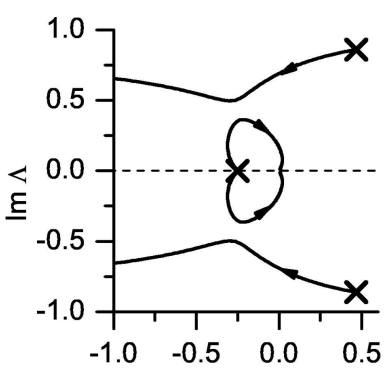

(b)

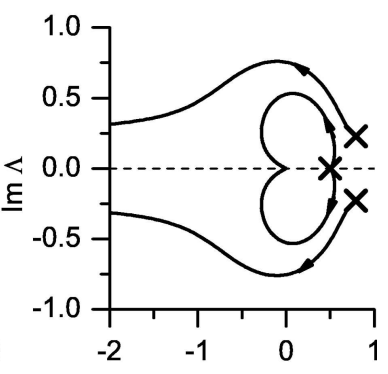

(d)

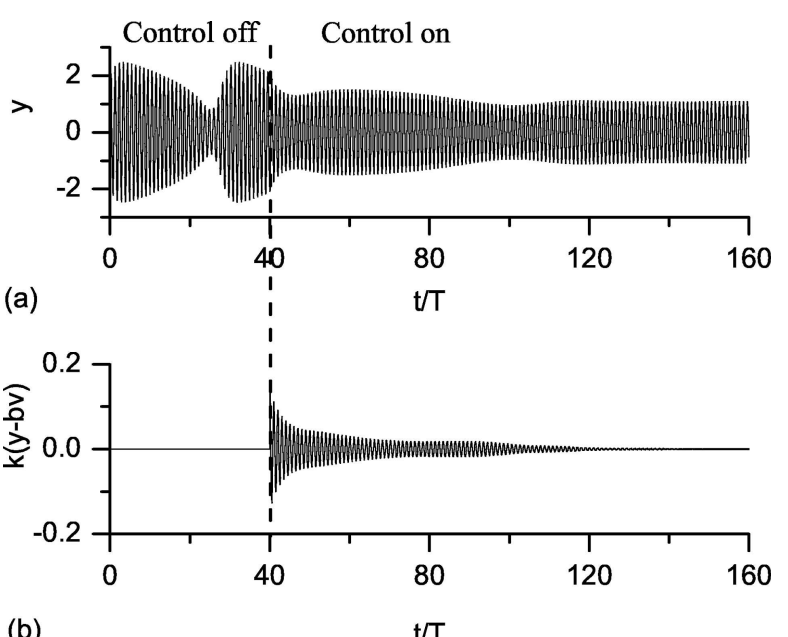

(b)

Fig. 4. Numerical simulation of Eqs. (4)-(7) for $(\nu, \alpha)=$ $(0.9,0.6)$. The control perturbation is switched on at the moment $t_{\mathrm{c}}=40 T$, i.e., $k=0$ for $t<t_{\mathrm{c}}$ and $k=0.07$ for $t>t_{\mathrm{c}}$. (a) Dynamics of the output variable $y$. (b) Dynamics of the control perturbation $k(y-b v)$.

the fastest convergence to the stabilized orbit. Similar results are obtained in the region of three periodic orbits with the use of an unstable filter. Figures 3(c) and (d) show an evolution of the FEs of the smallest orbit for a set of parameters $(\nu, \alpha)=(0.25,0.3), \gamma=-0.5$, and $\nu_{\mathrm{c}}=0$. Now the interval of stability is infinite, $\kappa_{1}<\kappa<\infty, \kappa_{1} \approx 1.525$, and the optimal value of the control gain is $\kappa_{\mathrm{opt}} \approx 2.55$.

\section{Dynamics of the controlled system}

To support the above linear analysis we have performed numerical simulations of the original nonlinear system (4)-(7). The results for a set of parameters $(\nu, \alpha)=(0.9,0.6)$ and $\varepsilon=0.1$ are shown in Fig. 4. In this case the uncontrolled system has a single UPO with the amplitude $\left|A_{0}\right| \approx 1.034$ and the FEs $\lambda_{0}=\varepsilon \Lambda_{0} / 2 \approx$ $0.0233 \pm 0.0430 \mathrm{i}$. To stabilize this orbit we use a stable controller with the parameter $\gamma=0.25$ or $b=\varepsilon \gamma=$ 0.025 . We demonstrate successful stabilization for an optimal value of the control gain $k=k_{\mathrm{opt}}=\varepsilon \kappa_{\mathrm{opt}}=$ 0.07 . Without control $\left(t<t_{\mathrm{c}}=40 T\right)$ the forced oscillator exhibits a beat phenomenon. The control perturbation removes the beat, and after a transient the synchronous regime with the external force is restored. The control perturbation becomes extremely small whenever the oscillator reaches a previously unstable orbit.

Figure 5 shows a control of the oscillator for a set of parameters $(\nu, \alpha)=(0.25,0.3), \varepsilon=0.1$, when the system has three periodic orbits. The largest orbit 


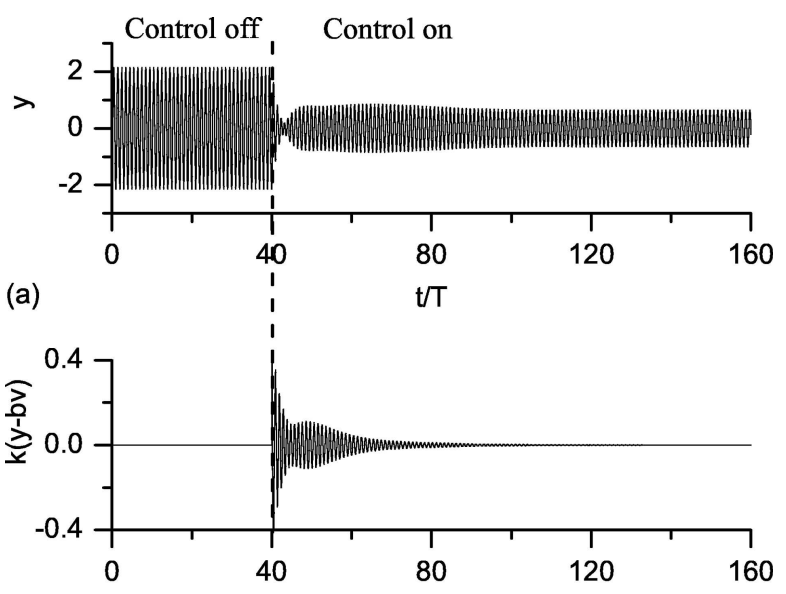

(b)

$\mathrm{t} / \mathrm{T}$

Fig. 5. Same diagrams as in Fig. 4 but for $(\nu, \alpha)=(0.25,0.3)$.

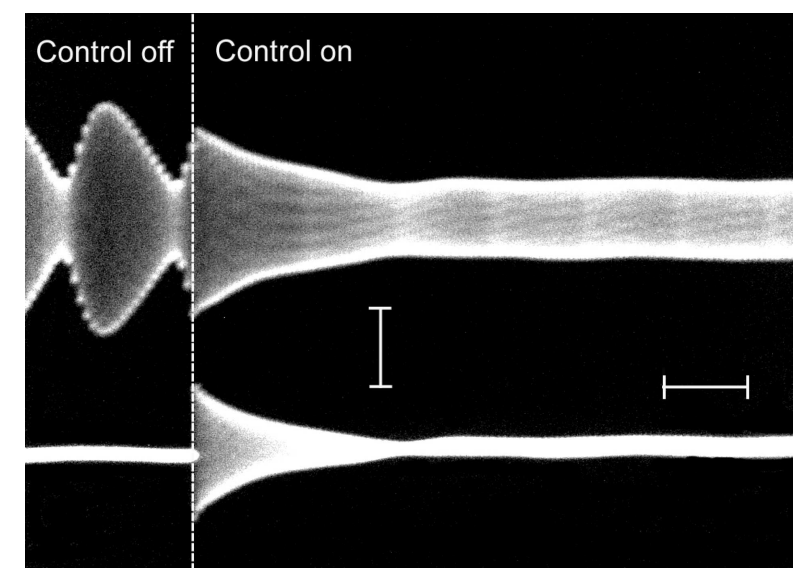

Fig. 6. Experimental results for the stable controller.

with the amplitude $\left|A_{0}\right| \approx 2.12$ is stable. It corresponds to the synchronized periodic motion of the system that is observed without control for $t<t_{\mathrm{c}}=40 T$. The smallest orbit with the amplitude $\left|A_{0}\right| \approx 0.645$ is unstable; its two complex conjugate FEs are $\lambda_{0} \approx$ $(0.0396 \pm 0.0114 \mathrm{i})$. This orbit is impossible to stabilize with the stable filter and therefore we use an unstable controller with the parameter $b=\varepsilon \gamma=-0.05$. Again we show the dynamics for an optimal value of the control gain $k=k_{\mathrm{opt}}=\varepsilon \kappa_{\mathrm{opt}}=0.255$. The unstable controller switches the system from synchronized motion with a large amplitude to another synchronized motion with a small amplitude. When this new synchronization regime is settled the feedback perturbation almost vanishes.

The suggested control technique has been demonstrated experimentally using the setup depicted in Fig. 6 of Ref. [10]. The experimental results are presented in Figs. 6 and 7. They are in a good agreement with the numerical results shown in Figs. 4 and 5, respectively.

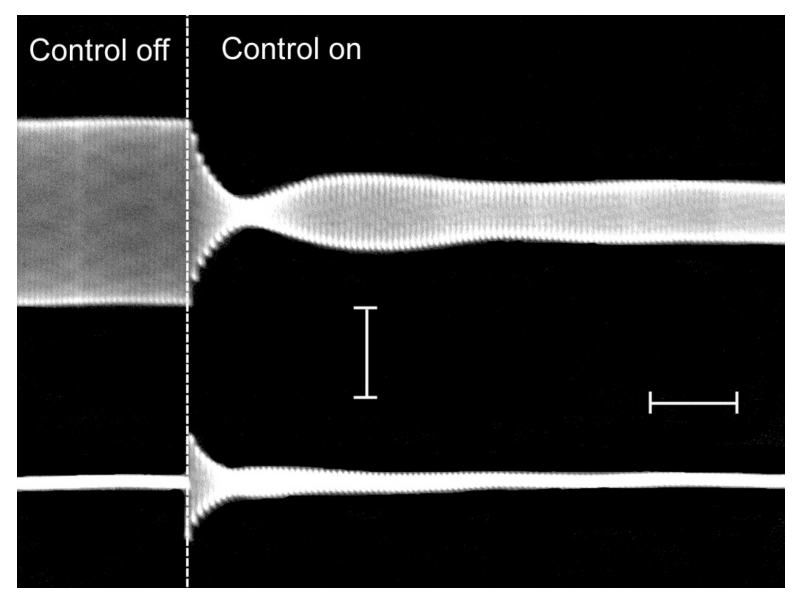

Fig. 7. Same results as in Fig. 6 but for the unstable controller.

\section{Conclusions}

We have applied a simple model-independent method for non-invasive control of synchronization region of a periodically forced self-sustained oscillator. The controller is based on a second order active filter incorporated in the feedback loop, which stabilizes unstable periodic orbits lying outside the synchronization region. By the method of averaging the analytical conditions for the controller parameters have been derived, which guarantee an extension of the synchronization region with only small control perturbation. We have considered both the stable and unstable filters and have shown that the unstable filter is more efficient in the case of small amplitudes of the driving force.

Although our theoretical analysis is restricted to the case of a specific example of the van der Pol oscillator, the main results and the theoretical approach presented here are valid for any self-sustained oscillator close to the Hopf bifurcation point. In our analysis, we have considered sinusoidal external force, however, the results can be easily generalized for non-sinusoidal periodic force. In the vicinity of the Hopf bifurcation only the first harmonic of the external force is relevant such that all formulas remain valid with the only difference that the force amplitude has to be interpreted as the amplitude of the first harmonic (see Ref. [1]).

We have demonstrated experimentally the efficiency of the control technique for an electronic circuit. A good agreement with the theoretical results has been obtained for both stable and unstable controllers. The experimental results demonstrate the universality of the applied algorithm, since the experimental selfsustained oscillator differs from the van der Pol oscillator. The experiment also confirms the robustness of the method against noise and small inaccuracy in the controller parameters. 
To compare this method with two other recently proposed DFC [7] and BTC [8] methods, we first note that the present method as well as the DFC are based on model-independent algorithms, while the BTC requires the knowledge of the system equations. However, the BTC algorithm is most efficient in the sense that it provides the fastest convergence to the stabilized periodic orbit in the extended region of synchronization. Thus if the model equations of the oscillator are known the best choice would be the BTC algorithm. In the case of unknown model equations the DFC or the present method can be chosen. The present method has an obvious advantage of a simple experimental implementation. It is superior to the DFC in the region of small amplitudes of the external force when using an unstable filter. The DFC advantage is that in an ideal case it turns the control perturbation exactly to zero. For the present method, the control perturbation vanishes only in approximation of averaged equations. For the DFC method, all harmonics of the unstable orbit pass through the feedback loop unchanged, while the second order filter preserves unchanged only the first harmonic and may change higher harmonics. However, close to the Hopf bifurcation the higher harmonics are small and the control perturbation in the present method is also extremely small.

\section{References}

[1] A. Pikovsky, M. Rosenblum, and J. Kurths, Synchronization: A Universal Concept in Nonlinear Sciences (Cambridge University Press, Cambridge, 2001).

[2] L. Glass, Synchronization and rhythmic processes in physiology, Nature 410, 277-284 (2001).

[3] H. Nijmeijer and A. Schaft, Nonlinear Dynamical Control Systems (Springer, New York, 1996).

[4] K. Ogata, Modern Control Engineering (PrenticeHall, New York, 1997).

[5] E. Ott, C. Gregory, and J.A. Yorke, Controlling chaos, Phys. Rev. Lett. 64, 1196-1199 (1990).

[6] Handbook of Chaos Control, ed. H.G. Shuster (WileyVCH, Weinheim, 1999).

[7] T. Pyragienè and K. Pyragas, Delayed feedback control of forced self-sustained oscillations, Phys. Rev. E 72, 026203-1-9 (2005).

[8] K. Pyragas, T. Pyragienė, A. Tamaševičius, and G. Mykolaitis, Control of forced self-sustained oscillations via a backward time controller, Phys. Lett. A 350, 349-354 (2006).

[9] K. Pyragas, Continuous control of chaos by selfcontrolling feedback, Phys. Lett. A 170, 421-428 (1992).

[10] T. Pyragienè, K. Pyragas, A. Tamaševičius, and G. Mykolaitis, Non-invasive control of synchronization region of a forced self-oscillator via a second order filter, Phys. Lett. A 361, 323-331 (2007).

\title{
SINCHRONIZACIJOS VALDYMAS ANTROS EILĖS FILTRO VALDIKLIU
}

\author{
T. Pyragienè, K. Pyragas, A. Tamaševičius, G. Mykolaitis \\ Puslaidininkiu fizikos institutas, Vilnius, Lietuva
}

\begin{abstract}
Santrauka
Vienas labiausiai nagrinėjamų netiesinės dinamikos objektų yra sąveikaujantys savaiminių virpesių osciliatoriai. Tokiose sistemose stebimi įdomūs reiškiniai. Sinchronizacija yra vienas iš jų. Dèl praktinès ir mokslinès svarbos sinchronizacija tapo viena iš intensyviai nagrinejjamų netiesinès dinamikos sričių. Kai sistemos parametrai dreifuoja, pageidaujamas sinchronizacijos režimas gali išnykti ir atsirasti mūšos reiškinys. Sinchronizaciją galima atstatyti, panaudojant neinvazinio valdymo metodus - žinomą uždelstojo grįžtamojo ryšio metodą [7] ir neseniai pasiūlytą apgręžto laiko valdikli [8].
\end{abstract}

Kartais valdomos sistemos modelis yra nežinomas. Šiuo atveju apgręžto laiko valdiklis netinka, o uždelstojo grįžtamojo valdymo metodo realizavimas nèra labai paprastas. Mes pasiūlème naują neinvazinio valdymo algoritmą, kuriam modelio žinojimas nereikalingas ir kuri paprasta eksperimentškai igyvendinti. Naujas valdikis yra sukonstruotas taikant antros eilès filtrą. Sinchronizuojant originaluji osciliatorių su filtru, galima stabilizuoti jo nestabilią periodinę orbitą ir tokiu būdu priversti ji sinchronizuotis su išorine periodine jèga. 